\title{
Performance of diagnostic ultrasound to identify causes of hydramnios.
}

Marie-José Adam ${ }^{1}$, Isabelle Enderle ${ }^{1,6}$, Gwenaëlle Le Bouar ${ }^{1}$, Anne-Sophie Cabaret-Dufour ${ }^{1}$, Cécile Tardif ${ }^{1}$, Laurence Contin ${ }^{1}$, Alexis Arnaud ${ }^{2}$, Maïa Proisy ${ }^{3}$, Sylvie Jaillard ${ }^{4}$, Laurent Pasquier $^{5}$, Maela Le Lous ${ }^{1,6}$.

1. Department of Obstetrics and Gynecology, University Hospital of Rennes.

2. Department of Pediatric Surgery, University Hospital of Rennes.

3. Department of Radiology, University Hospital of Rennes.

4. Department of Cytogenetics, University Hospital of Rennes.

5. Department of Genetics, Univers ity Hospital of Rennes.

6. CIC Inserm 1414, University Hospital of Rennes, University of Rennes 1, Rennes, France.

\section{Corresponding author:}

Dr Maela LE LOUS

maela.lelous@chu-rennes.fr,

Department of Obstetrics and Gynecology

University Hospital of Rennes

16 Boulevard de Bulgarie

35200 Rennes

Running Head : Hydramnios and Ultrasound

No.of words : 3472 , No.of figures and tables : 7

\section{Bulleted Statements :}


What's already known about this topic?

- -Hydramnios can be the consequence of a fetal abnormality (e.g. gastrointestinal obstruction), a maternal pathology (e.g. diabetes), or a placental pathology (e.g. chorioangioma). The diagnostic yield of ultrasonography in the presence of hydramnios is unclear.

What does this study add?

- A targeted ultrasound scan can detect the cause of hydramnios in the majority of cases

- Amniocentesis and MRI have modest added benefit.

\section{Data Availability Statement:}

Research data are available from the corresponding author upon request. 


\section{Abstract}

Introduction: We aimed to assess the diagnostic yield of ultrasonography in the identification of the etiology of hydramnios, and the added value of MRI or amniocentesis.

Methods: We conducted a single-center retrospective study including pregnancies with confirmed hydramnios (defined as deepest pocket $\geq 8 \mathrm{~cm}$ ) between January 2013 and May 2017. Twin pregnancies, secondary hydramnios discovered after the diagnosis of a causal pathology, and pregnancies of unknown outcome were excluded. All pregnancies underwent a targeted scan, and selected cases underwent MRI or amniocentesis.

Results: A total of 158 patients with confirmed hydramnios were included. Hydramnios was associated with a fetal pathology in 37 cases (23.4\%), with diabetes in 39 (24.6\%), isolated macrosomia in 16 (10.1\%), and considered idiopathic in 66 (41.7\%). Ultrasonography established a diagnosis of the underlying pathology in 73\% of cases. Amniocentesis was done in 31 cases (20\%) and it allowed diagnosis of chromosome anomalies, esophageal atresia, myotonic dystrophy congenital type, Prader-Willi syndrome, and Bartter syndrome. MRI was done in 15 cases (10\%) and it allowed one additional diagnosis of esophageal atresia. The diagnostic yields of MRI and amniocentesis were $91.7 \%$ and $95.2 \%$, respectively. There were 5 false positive diagnoses at ultrasonography, and 1 false positive diagnosis at MRI.

Conclusion: Hydramnios can be associated with a wide variety of underlying pathologies. Diagnostic ultrasound can attain a diagnosis in the majority of cases. Amniocentesis offers a valuable complementary assessment.

Keywords: Fetal Ultrasound, General cytogenetics, Fetal MRI 


\section{Introduction}

The prevalence of hydramnios is estimated to be between $0.7 \%$ and $2 \%$ of all pregnancies depending on the study ${ }^{1-3}$. Hydramnios is defined by a volume of amniotic fluid (AF) $>2$ L regardless of the gestational age ${ }^{4}$. On ultrasound, hydramnios is defined by an AF index (AFI) $\geq 25 \mathrm{~cm}^{5,6}$ or by a deepest pocket (DP) greater than or equal to $10 \mathrm{~cm}$, although some authors apply a DP cut-off of $\geq 8 \mathrm{~cm}^{7,8}$.

Hydramnios can reveal a wide variety of pathologies. Conventionally, three causes of hydramnios are possible: fetal malformations (in particular digestive atresia and cardiopathies), maternal pathologies (e.g. diabetes, alloimmunization), and placental pathologies (e.g. chorioangioma) ${ }^{9}$. However, no cause is found in as many as 40 to $60 \%$ of cases ${ }^{1,10}$. The risk of maternofetal anomalies increases with the severity of hydramnios 1,3,11. Consequently, any woman presenting hydramnios, particularly if moderate or severe, requires comprehensive assessment and appropriate monitoring.

On discovering hydramnios, a diagnostic ultrasound is performed to identify a potential fetal defect. The work-up is completed by biological maternal tests to detect alloimmunization, diabetes, or infection (parvovirus B19, cytomegalovirus). Symptoms suggestive of myasthenia or myotonic dystrophy type I congenital (Steinert's disease) can be revealed during a genetic consultation. Additionally, MRI is often carried out. Finally, depending on the couple's wishes, an amniocentesis can be performed to determine the karyotype, detect any AF infection, and for biochemical analysis for the diagnosis of esophageal atresia or mutations such as Steinert's disease or Prader-Willi syndrome 12,13. However, there are no official recommendations defining the additional examinations to be carried out in this setting.

Our main objective was to assess the performance of diagnostic ultrasound to identify the cause of hydramnios and the added value of MRI or amniocentesis. Our secondary objective was to list the pathologies revealed by hydramnios. 


\section{Material and methods}

Design

We carried out a single-center retrospective study at Rennes University Hospital, a tertiary maternofetal reference center. We included all patients referred to our center between January 2013 and May 2017 for a suspicion of hydramnios, with a DP of $\geq 8 \mathrm{~cm}^{7,8}$ and for which the neonatal outcome was known (delivery at Rennes University Hospital).

The exclusion criteria were multiple pregnancies, known fetal anomalies for which hydramnios appeared secondarily during the follow-up of the causal pathology.

The study received the approval of the local ethics committee $\left(\mathrm{N}^{\circ} 20-27\right)$.

\section{Protocol}

The protocol for routine ultrasound included a first trimester ultrasound scan between 11 and 13+6 WG, a second trimester ultrasound scan between 20 and 25 WG, and a third trimester ultrasound between 30 and 35 WG. In case of suspected hydramnios, the patient was referred for a targeted scan.

Local protocol for targeted scan included in addition to regular routine scan: particular attention to the placenta, nasal flow, neck, thyroid, thymus, esophagus, mobility and trophicity of limbs, four cavity chambers, interventricular septum, right cardiac outlet, left cardiac outlet, aortic arch, pulmonary venous drainage, head profile, choanes, corpus callosum, brain ventricles and gyration, cerebellum, vermis, choroid plexus, velocity in midcerebral artery.

If hydramnios was confirmed, the patients were screened for diabetes (oral glucose tolerance test of 75g), maternofetal alloimmunization (irregular agglutinins), and cytomegalovirus (CMV) and parvovirus B19 (maternal serology). Toxoplasmosis serology is already routinely performed every month in France.

Amniocentesis was then discussed with the couple for karyotyping, array-CGH, biochemical indexing for Bartter syndrome, enzymatic profiling for esophageal atresia. Total protein, alphafeto protein, digestives enzymes ( $\gamma$-glutamyl transpeptidase, l-leucineaminopeptidase, and alkaline phosphatase) and electrolytes were assessed. An esophagus atresia index was calculated, as well as a Bartter index ${ }^{14}$. Detection of CMV or parvovirus B19 
was assessed in the amniotic fluid depending on maternal serology. The interest of investigating for other genetic abnormalities was discussed during a genetic consultation.

Patients were monitored monthly until delivery. MRI was performed around 32 weeks of gestation when further exploration was needed, according to the opinion of the multidisciplinary staff. Amniotic fluid drainage was performed only if the patients were symptomatic (premature labor, respiratory or abdominal discomfort, dyspnea).

\section{Collected Data}

Data were collected from the ultrasound software "Xplore" with the following keywords: "hydramnios" and "excess of amniotic fluid". The following maternal clinical data were collected from the patient records: maternal age, height, weight, body mass index, parity, gestation, history of gestational diabetes, diagnosis of diabetes for the current pregnancy, maternal complications of hydramnios.

The following ultrasound data were collected: the severity of the hydramnios according to the DP measurement (DP between 8-10,10-12,12-16, >16cm), gestational age at hydramnios onset, mode of discovery of hydramnios, the data from the first trimester ultrasound, the first trimester screening for trisomy 21, data from second and third or any additional ultrasounds, the diagnosis retained. Macrosomia was defined as a fetal estimated weight above the $90^{\text {th }}$ percentile.

Additional biological assessment data were collected: diabetes screening with an oral glucose tolerance test of 75g, irregular agglutinins, CMV and parvovirus B19 serology, amniocentesis, and MRI.

Neonatal data were also collected: gestational age at birth, delivery mode, birth weight, Apgar score at 1, 5 and 10 minutes, $\mathrm{pH}$ and lactates, transfer to intensive care unit, and the presence of neonatal pathology in connection with hydramnios.

\section{Primary Endpoint}

The primary endpoint was the rate of detection of an underlying fetal or neonatal pathology. The prevalence of fetal anomalies was stratified according to the severity of hydramnios at the initial scan (DP between $8-12,12-16, \geq 16 \mathrm{~cm}$ ). 
Additionally, we compared "pathological" hydramnios, defined by the presence of a fetal anomaly or maternal diabetes, and "non-pathological" hydramnios by grouping the cases of idiopathic hydramnios with isolated macrosomia.

Statistical analysis

Data were compared using a $\chi^{2}$ test, or Fisher's if appropriate, for the qualitative parameters, and a Student's test for the quantitative parameters. The results were considered significant if $\mathrm{p}$ was $<0.05$. The diagnostic yields of ultrasonography, MRI and amniocentesis was calculated and expressed with their 95\% confidence intervals (95\% CI).

\section{Results}

During the study period, 402 patients underwent diagnostic ultrasound for suspected hydramnios. Among them, 225 cases of hydramnios were confirmed for a total of 17460 births over the period studied, representing a prevalence of $1.3 \%$. Among the 225 cases of confirmed hydramnios, 17 were excluded because they were twin pregnancies, 27 because hydramnios appeared during the monitoring of an identified causal pathology, and 23 whose neonatal outcome was not known. A total of 158 patients were therefore included (Figure 1).

The clinical and ultrasound characteristics of these 158 patients are described in Table 1. The causes of hydramnios were: a fetal or neonatal pathology in 37 cases (23.4\%); diabetes in 39 (24.6\%); isolated macrosomia in 16 (10.1\%); and hydramnios was considered idiopathic in 66 (41.7\%).

\section{Fetal or neonatal pathologies:}

The most frequent fetal or neonatal pathologies involved the gastrointestinal tract (n $=10,31.3 \%$ ) including six cases of esophageal atresia (18.8\%) (Figure 2.a) and four of duodenal stenosis (12.5\%) (Figure 2.b). Other fetal and neonatal pathologies are detailed in Table 2, including 3 cases of myopathies (Figure 2.c), 2 of choanal atresia (Figure 2.d and 2.e), and 3 of anemia (Figure 2.f). Five fetuses had aneuploidy (3 with trisomy 21, and 2 with trisomy 18). The mode of discovery of these pathologies is shown in Table 3. 
There were 7 terminations of pregnancies, at a mean gestational age of 32 weeks, 1 fetal death at $35+1$ weeks gestation, and 3 neonatal deaths.

Diagnostic yield of ultrasonography

Targeted ultrasound identified abnormal findings diagnostic or suggestive of the etiology of hydramnios in 73\% of cases (27/37) (Table 3). Certain missed diagnoses could have been amenable to prenatal detection or suspicion, such as anti $\mathrm{D}$ allo-immunization, bilateral choanal atresia, Trisomy 18 and esophageal atresia. The fetus with trisomy 18 presented with fetal growth restriction and choroid plexus cysts but the parents declined amniocentesis. For 6 other anomalies the ability of ultrasonography to detect or suspect the condition was limited (one case each of congenital myotonic dystrophy type I Steinert's disease, Prader-Willi syndrome, Bartter syndrome, deletion of the short arm of chromosome 4, and Alagille syndrome).

There were 5 unconfirmed suspicions of pathologies on ultrasound : 2 small for gestational age and one macrosomia who were eutrophic at birth, one suspicion of esophageal atresia with a healthy baby at birth, and one cases of pyelectasy with normal urinary tract at birth.

Additional diagnostic yield of amniocentesis

Among the 10 anomalies missed at targeted ultrasonography, five were detected antenatally by amniocentesis (one case each of congenital myotonic dystrophy type I Steinert's disease, Prader-Willi syndrome, Bartter syndrome, trisomy 18 and esophageal atresia), the diagnostic yield of ultrasound coupled with amniocentesis was 86.5\% (32/37) [95\% CI ] The only false positive of amniocentesis was a healthy newborn whose prenatal enzyme profile on AF analysis suggested esophageal atresia.

Additional diagnostic yield of fetal MRI (thoracoabdominal and cerebral)

Only one case of esophageal atresia not diagnosed by ultrasound was found with MRI. One potential missed diagnosis of MRI was represented by normal MRI findings in a fetus diagnosed at birth with unilateral choanal atresia and posterior cleft palate. There were no false positive MRI diagnoses. 
Five malformations were diagnosed only at birth (one case each of congenital myopathy, bilateral choanal atresia, anti-D alloimmunization, deletion of the short arm of chromosome 4, and Alagille syndrome).

Characteristics of pathological versus non-pathological hydramnios

Table 4 displays a comparison of the antenatal and postnatal characteristics of pregnancies affected by "pathological hydramnios" (maternal diabetes and maternofetal pathologies) with those of pregnancies with "non-pathological" hydramnios (isolated fetal macrosomia and idiopathic hydramnios). Patients with pathological hydramnios had a significantly higher BMI than patients with non-pathological hydramnios, had diagnosis of hydramnios made significantly earlier in pregnancy, and had more severe hydramnios than those in the non-pathological group .

The number of live births was significantly lower in the pathological group than in the non-pathological group, and babies had lower birth weight and were significantly more likely to require admission to an intensive care unit.

Delivery Mode:

A total of 11(6.9\%) patient underwent cesarean-sections during labor (4 for failed induction of labor, 5 for non-reassuring fetal heart rate monitoring, 1 for a suspicion of placental abruption, 1 for arrest of labor), and 4 (2.5\%) had elective c-sections (2 because of a scarred uterus, one for perineal protection, one for placenta praevia).

Prevalence of fetal anomalies according to the severity of hydramnios

The distribution of causes of hydramnios according to the AF volume is detailed in Table 5. The likelihood of some underlying fetal or neonatal pathology was significantly related to the severity of hydramnios. Among the four cases of severe hydramnios, with a DP $>16 \mathrm{~cm} 3$ had a fetal pathology and 1 was related to maternal diabetes. The risk of undetected anomalies at birth in the event of normal antenatal follow-up in our study was $4.1 \%$ (5 anomalies found at birth/(158-32 = 126 fetuses with normal follow-up) and only observed in cases where the DP was $\geq 10 \mathrm{~cm}$.

The special cases of patients with diabetes 
In our series, 40 patients with hydramnios were known to be diabetic: 13 of these had pre-existing diabetes and 27 had gestational diabetes. Four cases of diabetes were discovered during the evaluation of hydramnios. In one patient with well-controlled gestational diabetes, no obstetric history, normal nuchal translucency but absent first trimester aneuploidy screening, the ultrasound scan at 33 weeks showed a DP of $12 \mathrm{~cm}$ and an AFI of $32 \mathrm{~cm}$. The fetus was estimated eutrophic at 22 WG and the targeted scan was remarkable only for the presence of choroid plexus cysts. Amniocentesis was performed and revealed trisomy 18 resulting in a medical termination of pregnancy. In another patient with gestational diabetes well controlled by diet, ultrasound scan at 32 weeks revealed hydramnios, with a DP of $13 \mathrm{~cm}$ and an AFI of $32 \mathrm{~cm}$. The targeted ultrasound scan was considered normal. An amniocentesis was performed with an enzymatic profile suggestive of esophageal atresia. A fetal thoraco-abdominal MRI did not find a blind upper esophageal sac and the newborn was healthy. For two patients, diabetes was not diagnosed until the birth of their child. One of the children was born at $40+4$ weeks weighing 3830g and presented a convulsive encephalopathy in the first days of life, at which time a deletion on the short arm of chromosome 4 was detected (amniocentesis had been refused by the couple). The other child had persistent severe icterus in the first days of life, revealing chronic cholestasis, ultimately leading to diagnosis of Alagille syndrome by gene testing. The pregnancy was marked by type 2 diabetes, well controlled with insulin therapy. The fetus was assessed as being eutrophic, with no ultrasound abnormalities apart from hydramnios with a DP of $11 \mathrm{~cm}$. Finally, one patient with a well-controlled type 1 diabetes experienced a fetal death at 35 WG. The ultrasound found a DP of $10 \mathrm{~cm}$ and an AFI of $29 \mathrm{~cm}$ from $26 \mathrm{WG}$, without fetal anomalies. The etiological assessment performed after birth (autopsy + karyotype) was negative. 


\section{Discussion}

Targeted ultrasound scan can identify or suggest the etiology of hydramnios in $73.0 \%$ of cases with an underlying fetal or maternal pathology. In our series, the most frequent malformation causing hydramnios was esophageal atresia $(n=6)$, with five of the cases diagnosed by ultrasound, one by visualization of a distended hypopharynx, and the other suspected by a persistent non-visualization of the fetal stomach associated with the hydramnios. However, a "small stomach" is a subjective sign and can be associated with a wide range of pathologies ${ }^{15,16}$. Only the presence of a blind esophageal pouch is a certain diagnosis. A distended hypopharynx is a novel and sensitive sign that can lead to diagnosis of esophageal atresia (once in our series) ${ }^{17}$. It is worth noting that we did not find any cases of esophagus atresia in patients with a DP $<10 \mathrm{~cm}$. Duodenal atresia was also common and all were diagnosed by ultrasound with the presence a double bubble image of the stomach. Other pathologies diagnosed in our series were heart disease, cleft lip, chylothorax, diaphragmatic hernia, and Beckwith-Wiedmann syndrome. Choanal atresia was more difficult to diagnose with ultrasound - only one of the two cases in our series was detected - mainly because this is not a usual ultrasound plane of the systematic scan. This highlights the importance of examining the nasal flow by doppler ultrasound in patients with hydramnios. Other fetal malformations that may be responsible for hydramnios can be found on ultrasound. In 2014, in a series of 860 patients with hydramnios, Kollman et al reported that $8.5 \%$ of the fetuses had congenital anomalies, the most common being cardiac anomalies $(32.9 \%)^{13}$. There is a relatively high rate of anomalies in our series especially a high rate of esophageal atresia, compared to previous epidemiological studies. It is to notice that none of the pathologies in this series were cardiac, which is one of the most common pathologies to develop hydramnios ${ }^{18}$. Other fetal malformations have been described, such as hyperechoic kidneys associated with a mutation in the HNF-1- $\beta$ gene ${ }^{19}$. Placental anomalies are relatively common and should be investigated by ultrasound. In our series, we found one case of chorioangioma (benign tumor of the placenta) which can cause fetal hydrops if large 20,21 . Finally, some cases of hydramnios were due to a myopathy causing impaired fetal swallowing 22,23 . It is therefore interesting to examine fetal mobility and poor fetal muscle tone on ultrasound. In our series, one case of myotonic dystrophy Type I congenital (Steinert) was diagnosed by amniocentesis but it had been overlooked by ultrasound. 
According to the data in the literature, the anomalies most frequently missed by ultrasound are ultimately cardiac and digestive abnormalities ${ }^{18,24,25}$. We did not notice major cardiac anomalies in our series, possibly owing to the detailed evaluation of fetal cardiac anomaly which is routinely performed at the 20-25 WG fetal anatomy scan.

Finally, we found ultrasound of poor predictive value for diagnosing fetal macrosomia (PPV of 36.7\%). In all of our cases where macrosomia alone was responsible for hydramnios, the DP was always $<16 \mathrm{~cm}$. The prevalence of fetal macrosomia alone to explain hydramnios at birth was $10.1 \%$ in our series $(n=16)$. Other authors have shown an association between idiopathic hydramnios and fetal macrosomia ${ }^{26,27}$.

In our study, the severity and precocity of hydramnios appeared to be associated with the presence of underlying fetal pathologies. This is in agreement with another French series ${ }^{28}$ and other studies $3,11,29-31$.

In our study, MRI only modestly increased the diagnostic yield: a missed ultrasound diagnosis of esophageal atresia was detected on MRI. Another study also demonstrates the usefulness of MRI in the diagnosis of brain abnormalities associated with hydramnios ${ }^{32}$.

Amniocentesis plays a critical role in the evaluation of hydramnios, and it increased substantially the diagnostic yield (from $73 \%$ based on targeted ultrasonography to $86.5 \%$. Aneuploidy was found in $10 \%$ of fetuses with an abnormal ultrasound and in $1 \%$ of fetuses with normal ultrasound. This is consistent with the data in the literature reporting an association between chromosomal anomalies and hydramnios with 3.2\% of chromosomal anomalies being found after a normal ultrasound ${ }^{3334}$. Hydramnios can also signal the presence of microdeletional syndromes like DiGeorge or Prader-Willi syndromes ${ }^{35}$. Array-CGH may be useful to detect these. Studies have shown that the detection rate of esophageal atresia approaches $100 \%$, with a specificity of $98 \%$, when biochemical analysis of the amniotic fluid is performed measuring the total protein level reveals a $\gamma$-glutamyl transpeptidase index multiplied by alphafeto protein ${ }^{36-38}$. In our series, one case of esophageal atresia which was not diagnosed by ultrasound was detected at amniocentesis. Analysis of the AF can also point towards an antenatal diagnosis of Bartter's syndrome (severe polyuria, renal sodium loss and postnatal dehydration). If the total protein level and Bartter index (total protein level multiplied by the alpha-fetoprotein level) are low, the sensitivity and specificity of a positive diagnosis of Bartter 
syndrome are $93 \%$ and $100 \%$, respectively ${ }^{39}$. Aldosterone dosage would appear to be less relevant for diagnosis ${ }^{40}$.

During our study period the incidence of pregnancies presenting with hydramnios was 1.3\% at the Rennes University Hospital of which 119 (75.3\%) were mild (DP <12), 35 (22.2\%) moderate (DP 10-16), and four (2.5\%) severe (DP $\geq 16$ ). These findings are in agreement with data from two large retrospective studies: a 2002 study carried out by Dashe et al ${ }^{2}$, including 672 cases of hydramnios, found a prevalence of $0.7 \%$ with 446 mild (66\%), 145 moderate (22\%) and 81 severe (12\%) cases; and a 2007 study carried out by Bundgaard et al ${ }^{3}$ including 168 hydramnios, reported a prevalence of $2 \%$ of which $66.7 \%$ were moderate and $33.3 \%$ severe. In our series we discovered four cases of gestational diabetes. In 2017\%, Frank et al studied isolated hydramnios appearing in the 3rd trimester of pregnancy and found $4.8 \%$ of the patients had late onset gestational diabetes (all patients had screened negative for diabetes in the 2nd trimester) confirming the importance of screening patients with hydramnios for diabetes ${ }^{41}$. However, presence of maternal diabetes does not exclude other causes for hydramnios, as was the case for 3 of our patients; therefore, additional testing (e.g. MRI or amniocentes is) should also be considered.

Infectious assessment

All the women presenting with hydramnios in our center are assessed for infection, including CMV and parvovirus B19 serologies. Toxoplamosis serology is already routinely performed on all pregnancies in France at monthly follow-up obstetric visits. In our series, only one case of suspected CMV was diagnosed. The diagnostic benefit of maternal serologic testing for viral infections is therefore debatable: the association between hydramnios and CMV, for example, has never really been demonstrated ${ }^{42}$. Two other studies also seem to show that screening for parvovirus B19 and TORCH serologies is not useful for pregnancies with isolated hydramnios on ultrasound, especially if it is discovered in the 3rd trimester ${ }^{43,44}$.

\section{Idiopathic hydramnios}

The prevalence of idiopathic hydramnios in our series was $41.8 \%$ which is in agreement with the rates reported in the literature at between 40 and $60 \%{ }^{1,10,28}$. Idiopathic hydramnios is a diagnosis of exclusion, which can only be retained after an exhaustive 
assessment for other causes of hydramnios. In our series, no diagnoses of idiopathic hydramnio s was made for a DP $>16 \mathrm{~cm}$. Dashe et al showed that the risk of abnormalities discovered postnatally is $1 \%$ for mild, $2 \%$ for moderate and $11 \%$ for severe hydramnios in cases with normal fetal ultrasound ${ }^{2}$. Other studies, such as that of Drelin et al (39) in 2009, found up to 28.4\% of anomalies detected during the first year of life in newborns with idiopathic hydramnios, while Abele et al (40) found 9.3\% of anomalies in newborns with hydramnios considered as idiopathic, with the main abnormality being gastrointestinal atresia ${ }^{4546}$. In our series, 5(3.1\%) anomalies were detected in the postnatal period. A diagnosis of idiopathic hydramnios is not without implication for outcome. Even in the absence of a pathology explaining hydramnios, Asadi et al. reported a higher risk of low birth weight $(<2500 \mathrm{~g})$, macrosomia (>4000 g), but also admission to intensive care, fetal distress at birth, fetal death, and poor adaptation to extra-uterine life, premature birth and neonatal death in cases of idiopathic hydramnios compared to normal fluid pregnancies ${ }^{47}$. A 2020 French study also found $24.1 \%$ of unfavorable outcomes in cases of idiopathic hydramnios ${ }^{28}$. A meta-analys is combining 10 studies and nearly 200,000 patients with hydramnios also found a two-fold risk of retro-placental hematoma in pregnancies complicated by hydramnios ${ }^{48}$. Similarly, another study demonstrated a higher risk of gastro-intestinal morbidity in children with a history of hydramnios ${ }^{31}$. These data suggest that all women with hydramnios should be referred to a tertiary maternofetal care center for the diagnostic workup including a targeted diagnostic ultrasound scan, and offered an MRI and an amniocentesis for genetic and biochemical assessments.

Strengths and weaknesses

Our study has some obvious limitations inherent to its retrospective design including data loss, especially for those women who did not finally give birth in our center and who were excluded from the study. This could also present a selection bias because all the included patients gave birth in our tertiary referral maternofetal care center and were possibly more severe. At variance with other series, we did not find a high prevalence of CNS anomalies, which have been reported in up to $32 \%$ of cases of isolated polyhydramnios ${ }^{32}$. This could be due to the fact that fetal MRI was performed in only $9.5 \%$ of cases in our series. Similarly, amniocentesis was performed in only $20 \%$ of our cases: the yield of microarray in the presence 
of isolated hydramnios has been reported as 3.8\% ${ }^{49}$. In our series, 2 microdeletion syndromes were present (Prader-Willi and Beckwith-Wiedemann syndrome). Moreover, the absence of long-term follow-up might have masked some pathologies (e.g. myopathies or CNS pathologies) which could have become manifested later in life. However, the size of our sample of 158 patients makes it one of the largest series to date. Furthermore, the variety of pathologies described in our series revealed by hydramnios is of interest both for sonographers and for prenatal counselling.

\section{Conclusion}

Patients should be informed that appropriate work-up of hydramnios can reveal a wide variety of pathologies. Diagnostic ultrasound offers the most yield to identify or suspect the underlying cause (73\%). Amniocentesis offers an important complementary assessment looking for aneuploidies, microdeletion syndrome, Bartter syndrome, esophageal atresia and congenital myopathies. MRI had a limited role in our series: it may marginally improve the detection of esophagus atresia. Despite a meticulous prenatal diagnostic work-up, a small proportion of pathologies can only be diagnosed postnatally.

\section{Funding: none}

Conflicts of interest: none 


\section{References}

1. Magann EF, Chauhan SP, Doherty DA, Lutgendorf MA, Magann MI, Morrison JC. A review of idiopathic hydramnios and pregnancy outcomes. Obstet Gynecol Surv. 2007;62(12):795-802. doi:10.1097/01.0gx.0000290349.58707.e0

2. Dashe JS, McIntire DD, Ramus RM, Santos-Ramos R, Twickler DM. Hydramnios: anomaly prevalence and sonographic detection. Obstet Gynecol. 2002;100(1):134139.

3. Bundgaard A, Andersen BR, Rode L, Lebech M, Tabor A. Prevalence of polyhydramnios at a Danish hospital--a population-based study. Acta Obstet Gynecol Scand. 2007;86(12):1427-1431. doi:10.1080/00016340701447569

4. Magann EF, Morton ML, Nolan TE, Martin JN, Whitworth NS, Morrison JC. Comparative efficacy of two sonographic measurements for the detection of aberrations in the amniotic fluid volume and the effect of amniotic fluid volume on pregnancy outcome. Obstet Gynecol. 1994;83(6):959-962.

5. Phelan JP, Smith CV, Broussard P, Small M. Amniotic fluid volume assessment with the four-quadrant technique at 36-42 weeks' gestation. $J$ Reprod Med. 1987;32(7):540-542.

6. Alley MH, Hadjiev A, Mazneikova V, Dimitrov A. Four-quadrant assessment of gestational age-specific values of amniotic fluid volume in uncomplicated pregnancies. Acta Obstet Gynecol Scand. 1998;77(3):290-294.

7. Chamberlain PF, Manning FA, Morrison I, Harman CR, Lange IR. Ultrasound evaluation of amniotic fluid volume. II. The relationship of increased amniotic fluid volume to perinatal outcome. Am J Obstet Gynecol.1984;150(3):250-254.

8. Manning FA, Platt LD, Sipos L. Antepartum fetal evaluation: development of a fetal biophysical profile. Am J Obstet Gynecol. 1980;136(6):787-795.

9. Sandlin AT, Chauhan SP, Magann EF. Clinical relevance of sonographically estimated amniotic fluid volume: polyhydramnios. J Ultrasound Med. 2013;32(5):851-863. doi:10.7863/ultra.32.5.851

10. Khan S, Donnelly J. Outcome of pregnancy in women diagnosed with idiopathic polyhydramnios. Aust N Z J Obstet Gynaecol. 2017;57(1):57-62. doi:10.1111/ajo.12578 
11. Lazebnik N, Many A. The severity of polyhydramnios, estimated fetal weight and preterm delivery are independent risk factors for the presence of congenital malformations. Gynecol Obstet Invest. 1999;48(1):28-32. doi:10129

12. Gilles Grangé, Fréderic Bargy. Guide Pratique de l'échographie Obstétricale et Gynécologique. 2e édition. sous l'égide du CNGOF

13. Kollmann M, Voetsch J, Koidl C, Schest E, Haeusler M, Lang U, Klaritsch P. Etiology and perinatal outcome of polyhydramnios. Ultraschall Med. 2014;35(4):350-356. doi:10.1055/s-0034-1366115

14. Muller F, Dommergues M, Ville Y, Lewin F, Delvalez-Morichon N, Nihoul-Fekete C, Bargy F, Dumez Y, Boue A. Amniotic fluid digestive enzymes: Diagnostic value in fetal gastrointestinal obstructions. Prenatal Diagnosis. 1994;14(10):973-979. doi:10.1002/pd.1970141013

15. Brumfield CG, Davis RO, Owen J, Wenstrom K, Kynerd PM. Pregnancy outcomes following sonographic nonvisualization of the fetal stomach. Obstet Gynecol. 1998;91(6):905-908. doi:10.1016/s0029-7844(98)00104-5

16. McKelvey A, Stanwell J, Smeulders N, Nasr R, Curry J, Pandya P. Persistent nonvisualisation of the fetal stomach: diagnostic and prognostic implications. Arch Dis Child Fetal Neonatal Ed. 2010;95(6):F439-442. doi:10.1136/adc.2009.179341

17. Tracy S, Buchmiller TL, Ben-Ishay O, Bamewolt CE, Connolly SA, Zurakowski D, Phelps A, Estroff JA. The Distended Fetal Hypopharynx: A Sensitive and Novel Sign for the Prenatal Diagnosis of Esophageal Atresia. J Pediatr Surg. 2018;53(6):1137-1141. doi:10.1016/j.jpeds urg.2018.02.073

18. Dashe JS, McIntire DD, Ramus RM, Santos-Ramos R, Twickler DM. Hydramnios: anomaly prevalence and sonographic detection. Obstet Gynecol. 2002;100(1):134139. doi:10.1016/s0029-7844(02)02013-6

19. Gondra L, Décramer S, Chalouhi GE, Muller F, Salomon R, Heidet L. Hyperechogenic kidneys and polyhydramnios associated with HNF1B gene mutation. Pediatr Nephrol. 2016;31(10):1705-1708. doi:10.1007/s00467-016-3421-6

20. Rodríguez-Ayala G, de la Vega A, Correa-Rivas M, Jímenez A. Chorioangioma: an uncommon cause of hydramnios and consequent preterm labor in second trimester of pregnancy. Bol Asoc Med P R. 2013;105(1):36-39.

21. Willis C, Fergus on S, Soydemir F. Placental chorioangioma associated with polyhydramnios and hydrops fetalis. BMJ Case Rep. 2019;12(1). doi:10.1136/bcr2018-227828 
22. Palmerio G, Rosaschino P, Castelli G, Zambetti E, Bianchi P, Martinelli D. [A rare cause of polyhydramnios: Steinert's syndrome. A clinical case report]. Minerva Ginecol. 1997;49(1-2):49-52.

23. Robyr R, Bernard J-P, Roume J, Ville Y. Familial diseases revealed by a fetal anomaly. Prenat Diagn. 2006;26(13):1224-1234. doi:10.1002/pd.1593

24. Abele H, Starz S, Hoopmann M, Yazdi B, Rall K, Kagan KO. Idiopathic polyhydramnios and postnatal abnormalities. Fetal Diagn Ther. 2012;32(4):251255. doi:10.1159/000338659

25. Yefet E, Daniel-Spiegel E. Outcomes From Polyhydramnios With Nomal Ultras ound. Pediatrics. 2016;137(2):e20151948. doi:10.1542/peds.2015-1948

26. Sohaey R, Nyberg DA, Sickler GK, Williams MA. Idiopathic polyhydramnios: association with fetal macrosomia. Radiology. 1994;190(2):393-396. doi:10.1148/radiology.190.2.8284386

27. Wiegand SL, Beamon CJ, Chescheir NC, Stamilio D. Idiopathic Polyhydramnios: Severity and Perinatal Morbidity. Am J Perinatol. 2016;33(7):658-664. doi:10.1055/s-0036-1571320

28. Bertholdt C, Fijean A-L, Morel O, Zuily-Lamy C. [Postnatal outcome from polyhydramnios without sonographic abnomalities]. Gynecol Obstet Fertil Senol. 2020;48(2):162-166. doi:10.1016/j.gofs.2019.11.004

29. Magann EF, Chauhan SP, Doherty DA, Lutgendorf MA, Magann MI, Morrison JC. A review of idiopathic hydramnios and pregnancy outcomes. Obstet Gynecol Surv. 2007;62(12):795-802. doi:10.1097/01.0gx.0000290349.58707.e0

30. Barkin SZ, Pretorius DH, Beckett MK, Manchester DK, Nelson TR, MancoJohnson ML. Severe polyhydramnios: incidence of anomalies. AJR Am J Roentgenol. 1987;148(1):155-159. doi:10.2214/ajr.148.1.155

31. Amitai A, Wainstock T, Sheiner E, Walfisch A, Landau D, Pariente G. The association between pregnancies complicated with isolated polyhydramnios or oligohydramnios and offspring long-term gastrointestinal morbidity. Arch Gynecol Obstet. 2019;300(6):1607-1612. doi:10.1007/s00404-019-05330-6

32. Fishel-Bartal M, Watad H, Hoffmann C, Achiron R, Barzilay E, Katorza E. Fetal brain MRI in polyhydramnios: is it justified? J Matern Fetal Neonatal Med. 2019;32(23):3986-3992. doi:10.1080/14767058.2018.1480605

33. Glantz JC, Abramowicz JS, Sherer DM. Significance of idiopathic midtrimester polyhydramnios. Am J Perinatol. 1994;11(4):305-308. doi:10.1055/s-2007-994599 
34. Brady K, Polzin WJ, Kopelman JN, Read JA. Risk of chromosomal abnormalities in patients with idiopathic polyhydramnios. Obstet Gynecol. 1992;79(2):234-238.

35. Devriendt K, Van Schoubroeck D, Eyskens B, Vantrappen G, Swillen A, Gewillig M, Dumoulin M, Moerman P, Vandenberghe K, Fryns JP. Polyhydramnios as a prenatal symptom of the digeorge/velo-cardio-facial syndrome. Prenat Diagn. 1998;18(1):68-72.

36. Muller C, Czerkiewicz I, Guimiot F, Dreux S, Salomon LJ, Khen-Dunlop N, Bonnard A, Schmitz T, Oury J-F, Muller F. Specific biochemical amniotic fluid pattern of fetal isolated esophageal atresia. Pediatr Res. 2013;74(5):601-605. doi:10.1038/pr.2013.131

37. Allaf B, Dreux S, Schmitz T, Czerkiewicz I, Le Vaillant C, Benachi A, HoufflinDebarge V, Maréchaud M, Oury J-F, Muller F. Amniotic fluid biochemistry in isolated polyhydramnios: a series of 464 cases. Prenat Diagn. 2015;35(13):13311335. doi:10.1002/pd.4700

38. Czerkiewicz I, Dreux S, Beckmezian A, Benachi A, Salomon LJ, Schmitz T, Bonnard A, Khen-Dunlop N, Muller F. Biochemical amniotic fluid pattern for prenatal diagnosis of esophageal atresia. Pediatr Res. 2011;70(2):199-202. doi:10.1203/PDR.0b013e318220c08a

39. Garnier A, Dreux S, Vargas-Poussou R, Oury J-F, Benachi A, Deschênes G, Muller F. Bartter syndrome prenatal diagnosis based on amniotic fluid biochemical analys is. Pediatr Res. 2010;67(3):300-303. doi:10.1203/PDR.0b013e3181ca038d

40. Rachid M, Dreux S, Pean de Ponfilly G, Vargas-Poussou R, Czerkiewicz I, Chevenne D, Oury J-F, Deschênes G, Muller F. Prenatal diagnosis of Bartter syndrome: amniotic fluid aldosterone. Ann Biol Clin (Paris). 2017;75(2):204-208. doi:10.1684/abc.2017.1229

41. Frank Wolf M, Peleg D, Stahl-Rosenzweig T, Kurzweil Y, Yogev Y. Isolated polyhydramnios in the third trimester: is a gestational diabetes evaluation of value?(). Gynecol Endocrinol. Published online May 10, 2017:1-4. doi:10.1080/09513590.2017.1323857

42. Yefet E, Ben Shmuel Y, Nachum Z. The association between polyhydramnios and CMV infection - retrospective cohort study. J Matern Fetal Neonatal Med. Published online November 20, 2019:1-7. doi:10.1080/14767058.2019.1691164

43. Pasquini L, Seravalli V, Sisti G, Battaglini C, Nepi F, Pelagalli R, Di Tommaso M. Prevalence of a positive TORCH and parvovirus B19 screening in pregnancies complicated by polyhydramnios. Prenat Diagn. 2016;36(3):290-293. doi:10.1002/pd.4769 
44. Fayyaz H, Rafi J. TORCH screening in polyhydramnios: an observational study. $J$ Matern Fetal Neonatal Med. 2012;25(7):1069-1072.

doi:10.3109/14767058.2011.622002

45. Dorleijn DMJ, Cohen-Overbeek TE, Groenendaal F, Bruinse HW, Stoutenbeek P. Idiopathic polyhydramnios and postnatal findings. J Matern Fetal Neonatal Med. 2009;22(4):315-320. doi:10.1080/14767050802531870

46. Abele H, Starz S, Hoopmann M, Yazdi B, Rall K, Kagan KO. Idiopathic polyhydramnios and postnatal abnormalities. Fetal Diagn Ther. 2012;32(4):251255. doi:10.1159/000338659

47. Asadi N, Khalili A, Zarei Z, Azimi A, Kasraeian M, Foroughinia L, Salehi A, Ravanbod HR, Davoodi S, Vafaei H. Perinatal outcome in pregnancy with polyhydramnios in comparison with normal pregnancy in department of obstetrics at Shiraz University of Medical Sciences. J Matern Fetal Neonatal Med. 2018;31(13):1696-1702. doi:10.1080/14767058.2017.1325864

48. Khazaei S, Jenabi $\mathrm{E}$. The association between polyhydramnios and the risk of placenta abruption: a meta-analysis. J Matern Fetal Neonatal Med. Published online January 24, 2019:1-6. doi:10.1080/14767058.2019.1566898

49. Sagi-Dain L, Maya I, Reches A, Frumkin A, Grinshpun-Cohen J, Segel R, Manor E, Khayat M, Tenne T, Banne E, Shalata A, Yonath H, Berger R, Singer A, BenShachar S. Chromosomal Microarray Analysis Results From Pregnancies With Various Ultrasonographic Anomalies. Obstet Gynecol. 2018;132(6):1368-1375. doi:10.1097/AOG.0000000000002975 
Figure 1. Flow Chart
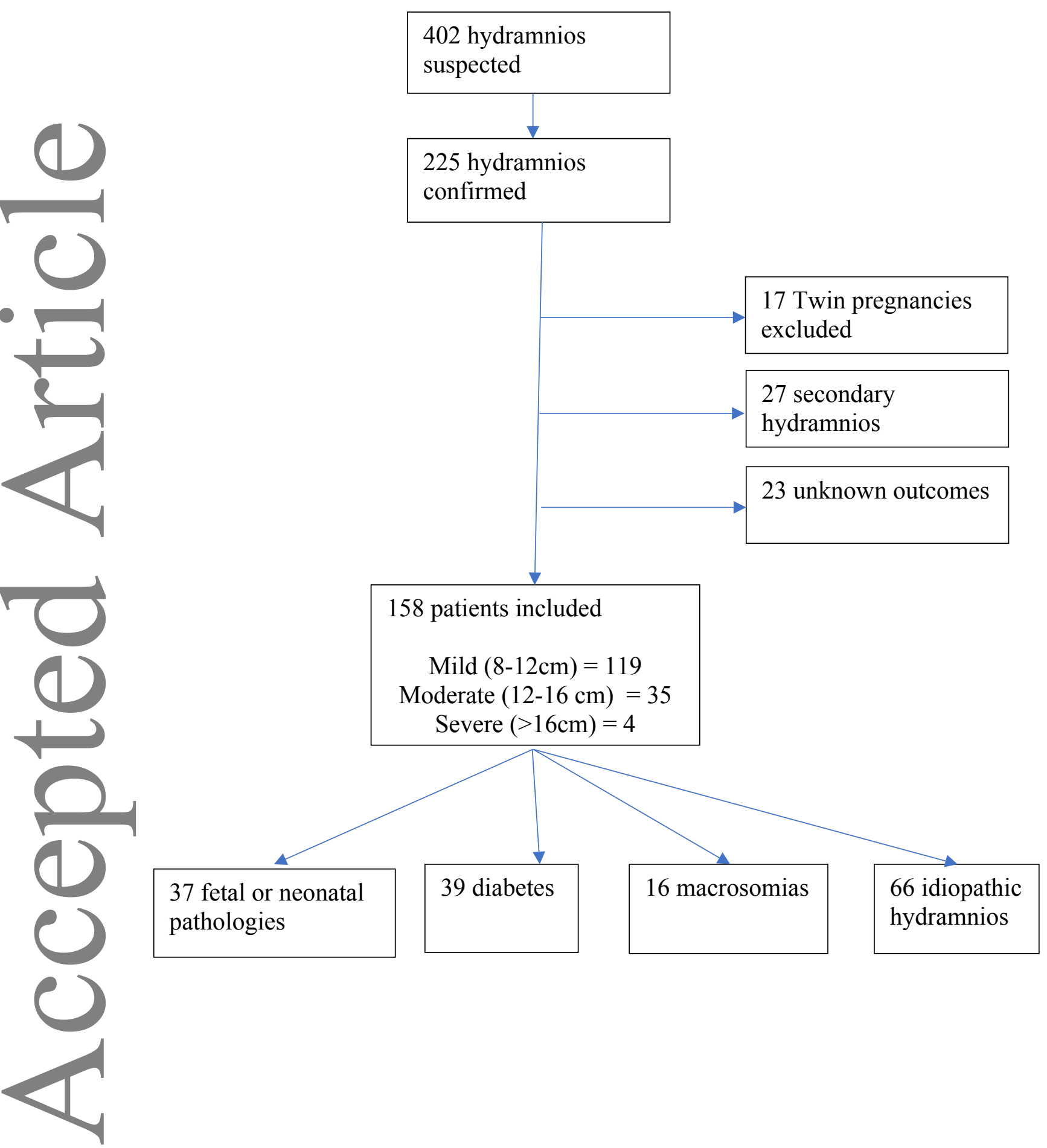
Figure 2.

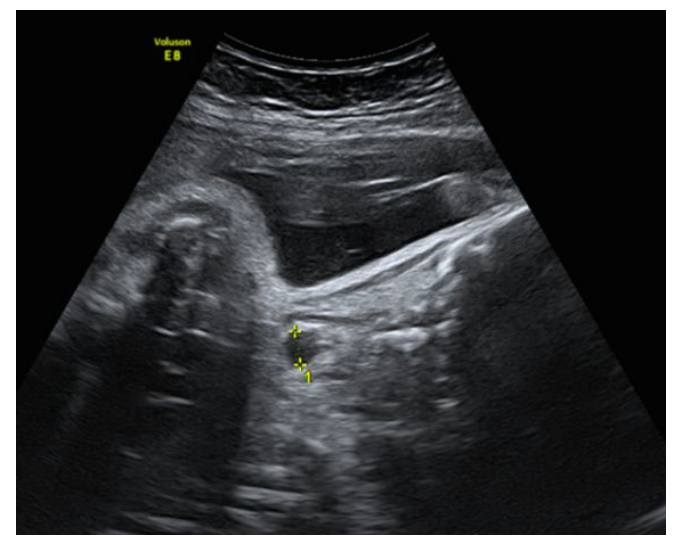

Fig 2-a. Distended hypopharynx caused by a lower esophageal atresia $32+2 \mathrm{WG}$ revealing esophageal atresia.

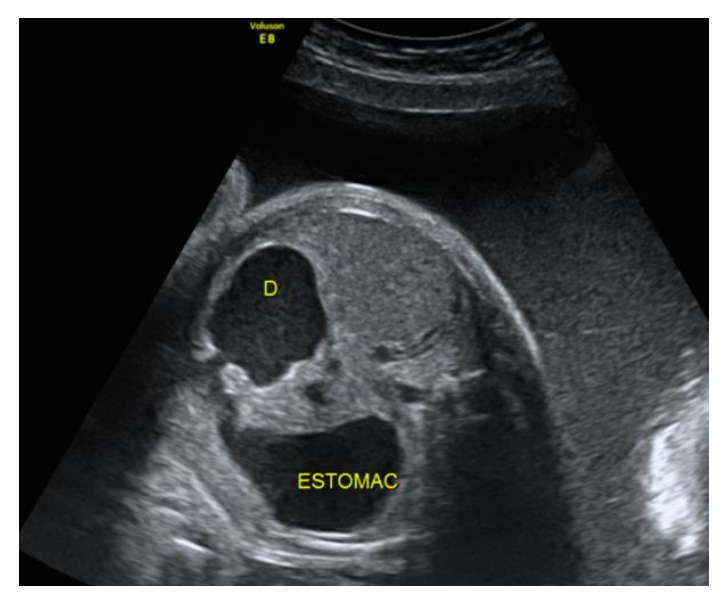

Fig 2-b. Double bubble : duodenum atresia

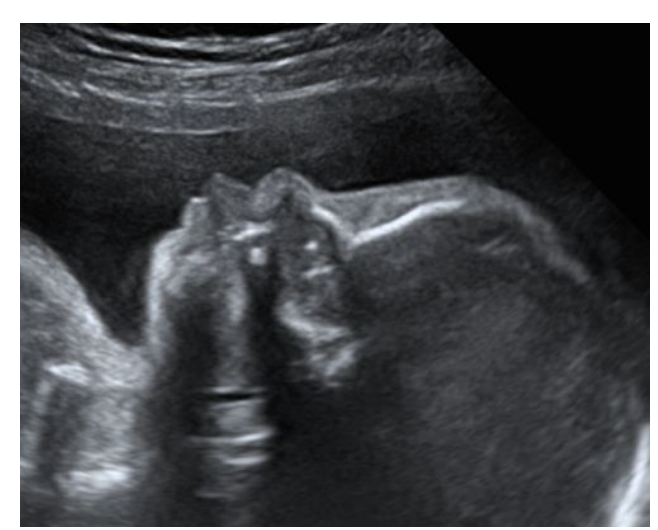

Fig 2-c. Profile, considered as normal at $28+1$ WG. Post natal diagnosis of a severe myopathy with hypotonia and retrognatism. 


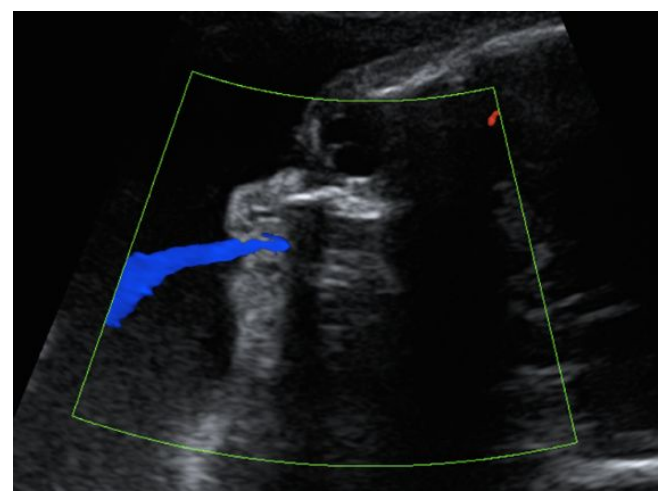

Fig 2-d. Unilateral nasal flow at $28+1 \mathrm{WG}$

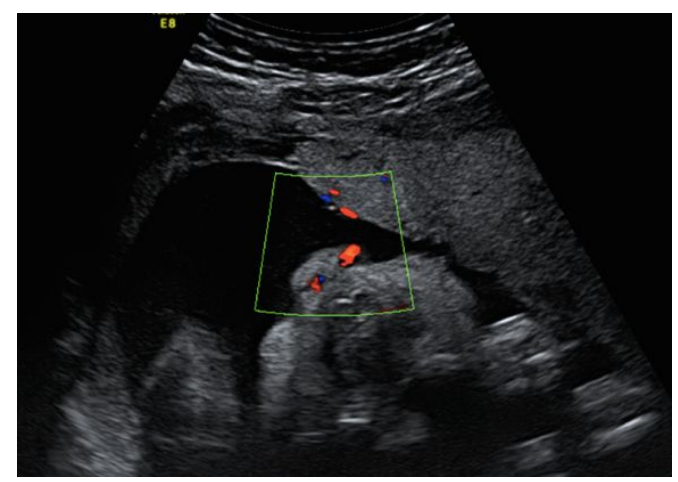

Fig 2-e. Normal bilateral nasal flow at $30 \mathrm{WG}$

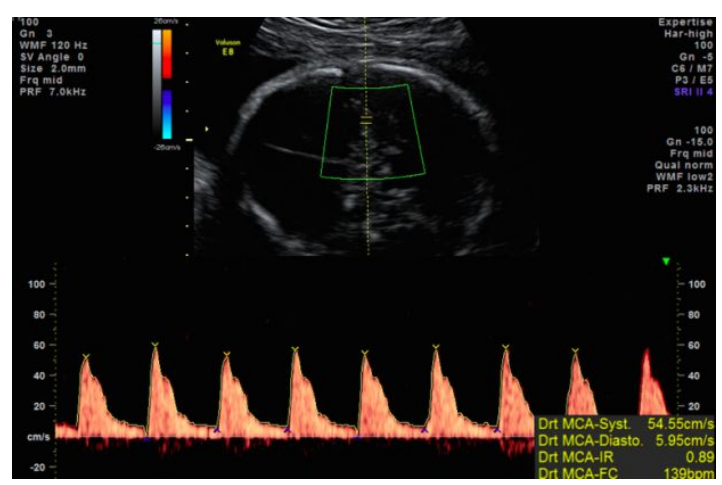

Fig 2-f. Systolic velocity in the middle cerebral artery at 30WG 
Table 1. Population characteristics

Population $\mathrm{N}=158$

Age (years)
BMI
Gravidity
Parity
History of gestational diabetes
Increased nuchal translucency
High-risk first trimester Trisomy 21 screening
Gestational age at hydramnios diagnosis (WG)
$\quad$ Min - max (WG)
Indications for ultrasound scan
$\quad$ Ultrasound
$\quad$ Uterine contractions
$\quad$ Increased uterine height
Hydramnios range (Single deepest pocket) cm
8 - 10
10 - 12
12 - 16
$\quad 16$

\section{Hydramnios check-up:}

Amniocentesis

$31(19.6 \%)$

Fetal MRI

$15(9.5 \%)$

Fetal tomodesitometry

$1(0.6 \%)$

Amniodrainage

$12(7.6 \%)$

Hydramnios complications

Threat of preterm labor n(\%)

$9(5.7 \%)$

Premature rupture of membranes n(\%)

$26(16.4 \%)$

Amniotic fluid embolism n(\%)

$1(0.6 \%)$

Fetal and neonatal outcomes

Live birth

$150(95 \%)$

Termination of pregnancy

$7(4.4 \%)$

Fetal death

$1(0.6 \%)$

Neonatal death

$3(1.9 \%)$

Gestational age at delivery (WG)

$38.9 \pm 2.0$

Min - max (WG)

$25-42$

Preterm labor $<37 \mathrm{WG}$

$31(19.6 \%)$

Fetal weight (g)

$3343 \pm 734$

$\operatorname{Min}-\max (\mathrm{g})$

$895-4935$

Macrosomia (>90e P).

$45(28.5 \%)$

Small for gestational age $(<10 \mathrm{e} \mathrm{P})$.

$13(8.3 \%)$

Mode of delivery: 
Vaginal birth

Elective C-section

C-section during labor

Neonatal outcomes:

Apgar $<7$ at 5 minutes $\mathrm{n}(\%)$

$\mathrm{pH}$

Lactates

Transfer to neonatal care

Neonatal follow-up duration (months)

Hydramnios cause :

Fetal or neonatal pathology

$37(23.4 \%)$

Diabetes

$39(24.7 \%)$

Macrosomia

$16(10.1 \%)$

$66(41.8 \%)$

Idiopathic hydramnios

DP: Deepest pocket, WG: weeks of gestation, T3: third trimester, MRI: Magnetic resonance imaging, P: percentile. 
Table 2. Types of Pathologies detected.

\begin{tabular}{ll}
\hline Pathology N=37 & $\mathbf{N}(\mathbf{\%})$ \\
\hline Fetal defects & \\
Oesophagus atresia & $6(18.8)$ \\
Duodenal atresia & $4(12.5)$ \\
Chylothorax & $2(6.3)$ \\
Fetal Supraventricular Tachycardia & $2(6.3)$ \\
Choanal atresia & $2(6.3)$ \\
Polymalformative syndrome & $2(6.3)$ \\
Left diaphragmatic hernia & $1(3.1)$ \\
Cleft lip & $1(3.1)$ \\
Cardiopathy & $1(3.1)$ \\
Hydrops & $1(3.1)$ \\
& \\
Myopathy & \\
Undocumented Myopathy & $1(3.1)$ \\
RYR1 Mutation & $1(3.1)$ \\
Steinert's disease & $1(3.1)$ \\
& \\
Anemia & \\
Anemia with fetal transfusion & $1(3.1)$ \\
RH alloimmunization & $1(3.1)$ \\
Cytomegalovirus infection & $1(3.1)$ \\
& \\
Genetic syndromes & \\
Beckwith-Wiedemann syndrome & \\
Prader-Willi syndrome & \\
Bartter's syndrome & $1(3.1)$ \\
Alagille syndrome & $1(3.1)$ \\
Deletion 4p- & $1(3.1)$ \\
Aneuploidies & $1(3.1)$ \\
Trisomy 21 & $1(3.1)$ \\
Prisomy 18 & \\
Chacental abnormality & $2(6.3)$ \\
\hline & $1(3.1)$ \\
& \\
& \\
& \\
& \\
&
\end{tabular}


Table 3. Fetal or neonatal pathologies and discovery mode, $n=37$ (32 antenatal and 5 postnatal)

\begin{tabular}{|c|c|c|c|c|}
\hline $\begin{array}{l}\text { Hydramnios } \\
\text { range }\end{array}$ & $\begin{array}{l}\text { Pathologies suspected on } \\
\text { diagnostic ultrasound } \\
\qquad \mathbf{n}=\mathbf{2 7}\end{array}$ & $\begin{array}{c}\text { Normal } \\
\text { ultrasound } \\
\text { pathology found } \\
\text { with } \\
\text { amniocentesis, } \\
n=5\end{array}$ & $\begin{array}{c}\text { Normal ultrasound } \\
\text { pathology found } \\
\text { with MRI } \\
n=1\end{array}$ & $\begin{array}{l}\text { Found at birth } \\
\qquad n=5\end{array}$ \\
\hline $\begin{array}{c}\text { DP 8-11 } \\
(n=18)\end{array}$ & $\begin{array}{l}\text {-Cleft lip } \\
\text {-Duodenal Stenosis } \\
\text {-Trisomy } 21 \\
\text {-Beckwith-Wiedemann } \\
\text {-Anemia } \\
\text {-Chorioangioma }\end{array}$ & - Steinert's disease & & $\begin{array}{l}\text {-Anti-D } \\
\text { alloimmunization } \\
\text {-Choanal atresia } \\
\text {-Alagille Syndrome }\end{array}$ \\
\hline $\begin{array}{c}\text { DP } 12-15 \\
(n=16)\end{array}$ & $\begin{array}{l}\text {-Unilateral choanal atresia } \\
\text {-3 esophageal atresia / } 2 \\
\text { duodenum atresia } \\
\text {-Hydrops (chylothorax) } \\
\text {-Left diaphragmatic hernia } \\
\text {-Myopathy } \\
\text {-Trisomy } 21 \\
\text {-Polymalformative sequence }\end{array}$ & $\begin{array}{l}\text {-Esophageal } \\
\text { atresia } \\
\text {-Prader-Willi Syndr } \\
\text {-Trisomy } 18\end{array}$ & $\begin{array}{l}\text { Eesophageal atresia } \\
\text { rome }\end{array}$ & $\begin{array}{l}\text {-Myopathy } \\
\text {-Deletion } \\
\text { chromosome 4p- }\end{array}$ \\
\hline $\begin{array}{c}\mathrm{DP} \geq 16 \\
(\mathrm{n}=3)\end{array}$ & $\begin{array}{l}\text {-Suspected CMV } \\
\text {-Fetal tachycardia }\end{array}$ & $\begin{array}{l}\text {-Bartter 's } \\
\text { syndrome }\end{array}$ & 0 & 0 \\
\hline
\end{tabular}

DP : Deepest pocket of amniotic fluid ; CMV cytomegalovirus 
Table 4. Pathological versus non-pathological hydramnios.

Age
BMI
Gravidity
Parity
Gestational Diabetes history
increased nuchal translucency
High risk first trimester screening
Gestational age at hydramnios diagnosis (WG)

Min - max (WG)

\begin{tabular}{|c|c|c|}
\hline $\begin{array}{c}\text { Pathological hydramnios } \\
\mathrm{N}=76\end{array}$ & $\begin{array}{c}\text { Non-pathological hydramnios } \\
\mathrm{N}=82\end{array}$ & p \\
\hline $30.7 \pm 6.1$ & $29.4 \pm 4.9$ & 0.129 \\
\hline $26.9 \pm 6.5$ & $24.4 \pm 4.7$ & 0.008 \\
\hline $3.2 \pm 2.1$ & $2.9 \pm 1.9$ & 0.44 \\
\hline $1.4 \pm 1.6$ & $1.2 \pm 1.2$ & 0.42 \\
\hline $2(50 \%)$ & $2(50 \%)$ & 1 \\
\hline $1(50 \%)$ & $1(50 \%)$ & 1 \\
\hline $2(66.6 \%)$ & $1(33.4 \%)$ & 0.94 \\
\hline $30 \mathrm{SA} \pm 4 \mathrm{SA}$ et $6 \mathrm{j}$ & $31 \mathrm{SA}$ et $2 \mathrm{j} \pm 4 \mathrm{SA}$ et $3 \mathrm{j}$ & 0.05 \\
\hline $22-38$ & $22-40$ & \\
\hline $48(63.1 \%)$ & $70(85.4 \%)$ & 0.0026 \\
\hline $24(31.6 \%)$ & $12(14.6 \%)$ & \\
\hline $4(5.2 \%)$ & $0(0 \%)$ & \\
\hline $9(11.8 \%)$ & $3(3.7 \%)$ & 0.069 \\
\hline $7(9.2 \%)$ & $2(2.5 \%)$ & 0.089 \\
\hline $16(21.0 \%)$ & $10(12.2 \%)$ & 0.197 \\
\hline $1(1.3 \%)$ & $0(0 \%)$ & 0.48 \\
\hline $65(85.5 \%)$ & $82(100 \%)$ & $<0.001$ \\
\hline $7(9.2 \%)$ & $0(0 \%)$ & 0.005 \\
\hline $1(1.3 \%)$ & $0(0 \%)$ & 0.48 \\
\hline $3(4 \%)$ & $0(0 \%)$ & 0.108 \\
\hline $37 \mathrm{SA}$ et $1 \mathrm{j} \pm 3 \mathrm{SA}$ et $2 \mathrm{j}$ & $39 \mathrm{SA} \pm 1 \mathrm{SA}$ et $6 \mathrm{j}$ & \\
\hline $25 \mathrm{SA}-41 \mathrm{SA}$ et $4 \mathrm{j}$ & $34 \mathrm{SA}-41 \mathrm{SA}$ et $6 \mathrm{j}$ & \\
\hline $3169 \pm 897$ & $3499 \pm 504$ & 0.004 \\
\hline $895-4935$ & $2100-4615$ & \\
\hline $29(38.2 \%)$ & $16(19.5 \%)$ & 0.013 \\
\hline $9(11.8 \%)$ & $4(4.8 \%)$ & 0.140 \\
\hline $50(65.8 \%)$ & $56(68.2 \%)$ & 0.865 \\
\hline $9(11.8 \%)$ & $10(12.2 \%)$ & 1 \\
\hline $17(22.4 \%)$ & $16(19.5 \%)$ & 0.698 \\
\hline $6(7.9 \%)$ & $2(2.4 \%)$ & 0.14 \\
\hline $7.22 \pm 0.1$ & $7.22 \pm 0.1$ & 0.96 \\
\hline $4 \pm 3.9$ & $4.1 \pm 1.8$ & 0.91 \\
\hline $23(35.4 \%)$ & $5(6 \%)$ & $<0.001$ \\
\hline $12(1-40)$ & $1(0.2-40)$ & $<0.001$ \\
\hline
\end{tabular}


Table 5. Etiologies by polyhydramnios severity

\begin{tabular}{|c|c|c|c|c|c|c|}
\hline $\begin{array}{l}\text { Hydramnios } \\
\text { range } \\
\text { Deepest pocket } \\
(\mathrm{cm})\end{array}$ & $\begin{array}{c}\text { Total } \\
\mathrm{N}(\%) \\
\mathrm{N}=158\end{array}$ & $\begin{array}{c}\text { Diabetes } \\
\mathrm{n}=39\end{array}$ & $\begin{array}{c}\text { Fetal or neonatal } \\
\text { pathology } \\
\text { n }=32+5\end{array}$ & $\begin{array}{l}\text { Macrosomia } \\
\mathrm{n}=16\end{array}$ & $\begin{array}{l}\text { Idiopathic Hydramnios } \\
\qquad \mathrm{n}=66\end{array}$ & $\mathrm{p}$ \\
\hline $8,0-11.9$ & $118(74.7)$ & $30(25.4)$ & $15+3(15.2)$ & 14 (11.9) & $56(47.5)$ & 0.002 \\
\hline $12-15.9$ & $36(22.8)$ & $8(22.2)$ & $14+2(44.4)$ & $2(5.6)$ & $10(27.8)$ & \\
\hline 16.0 & $4(2.5)$ & $1(25.0)$ & $3(75.0)$ & $0(0 \%)$ & $0(0 \%)$ & \\
\hline
\end{tabular}

Bold: post-natal diagnosis

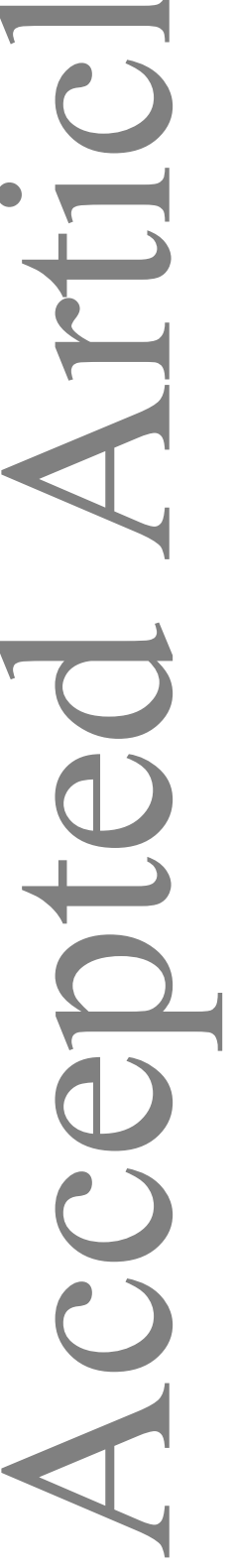

